\title{
Starke ambulante Medizin macht Alterung bezahlbar
}

\author{
Eine Studie des ZI sieht ein Milliarden-Einsparpotenzial durch niedergelassene Ärzte. Demnach \\ entlaste eine hohe Arztdichte in der ambulanten Versorgung den teuren Kliniksektor und mildere \\ die Kosten einer alternden Gesellschaft.
}

$\mathrm{E}$ ine hohe Arztdichte in der ambulanten Versorgung kann dazu beitragen, die steigende Morbidität in einer alternden Gesellschaft finanzierbar zu halten. Würde überall in Deutschland eine Best-Practice-Versorgung realisiert, könnten 2020 bis zu 2 Milliarden $€$, bis 2030 sogar 4 Milliarden $€$ eingespart werden. Das sind Ergebnisse einer Simulationsrechnung des Zentralinstituts für die kassenärztliche Versorgung (ZI). Dabei hat das ZI 21 Landkreise und kreisfreie Städte mit hoher Arztdichte als Best-Practice-Regionen identifiziert: Hier liegt die Inanspruchnahmerate der Vertragsärzte um 13\% über dem Bundesdurchschnitt, die der Kliniken um 15\% unter dem Durchschnitt.

Bleibt es bei der gegenwärtigen Versorgungsstruktur, dann würden allein die demografiebedingten Mehrkosten im stationären Sektor bis zum Jahr 2020 mit einem Plus von $6 \%$ oder 3 Milliarden $€$ zu Buche schlagen. Im ambulanten Sektor betrügen die Mehrkosten 3\% oder 1 Milliarde $€$. Würde es aber gelingen, überall Best-Practice-Standard zu realisieren, dann könnten die Klinik- kosten um 3 Milliardeı dert werden. Dagegen $n$ Intensivierung der ar lanten Medizin mit $5 \mathrm{M}$ liarden $€$ Mehrkoster verbunden. Damit würde das Kostenplus nur 2 Milliarden $€$ betragen. Helmut Laschet

Best-Practice-Regionen in Deutschland: Starke ambulante Versorgung, geringe Inanspruchnahm von Klinikleistungen

Quelle: Zentralinstitut für die kassenärztliche Versorgu Grafik: ÄrzteZeitung

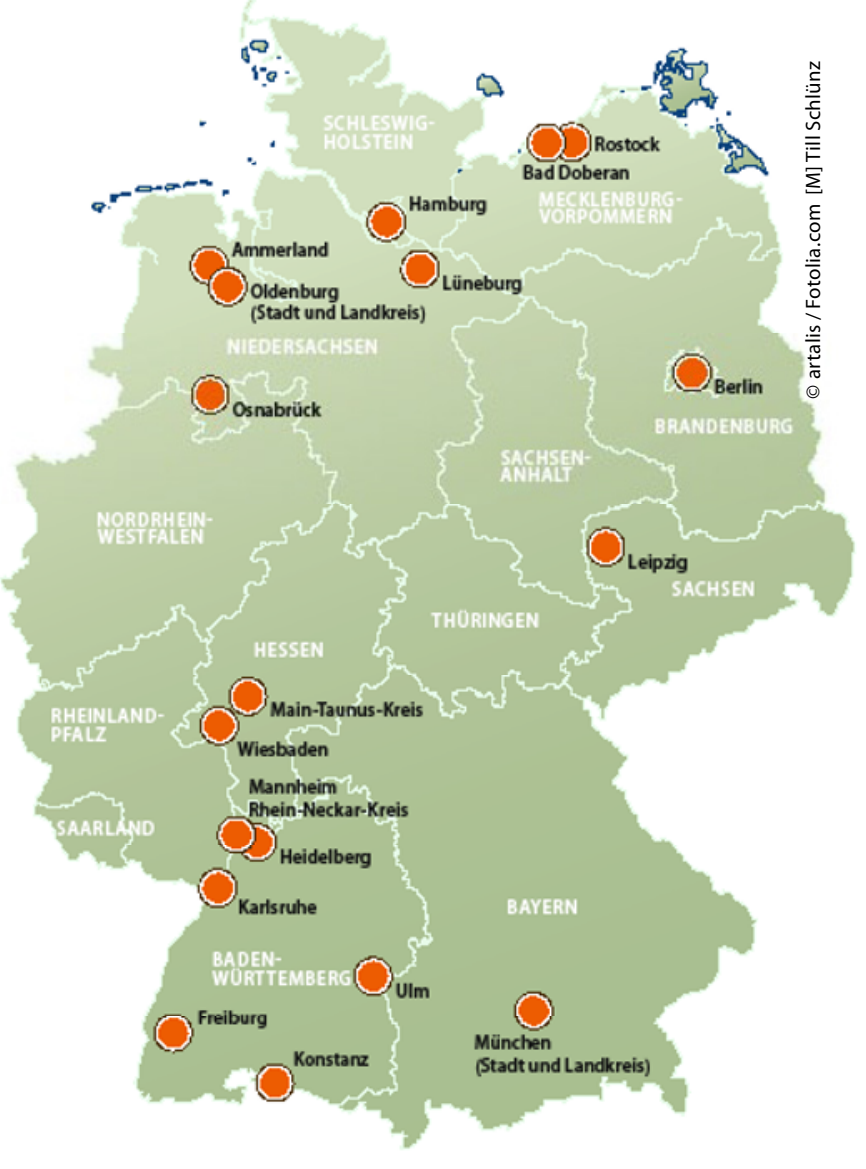

\section{Fehler im Morbi-RSA - Neuberechnung für 2013}

Das Landessozialgericht Nordrhein-Westfalen verdonnert das Bundesversicherungsamt zur Neuberechnung des Morbi-RSA für dieses Jahr.

$\mathrm{D}$ as Bundesversicherungsamt (BVA) muss Fehler im morbiditätsorientierten Risikostrukturausgleich (MorbiRSA) beheben und die Zuweisungen für die Krankenassen aus dem Gesundheitsfonds für dieses Jahr neu berechnen. Das hat das Landessozialgericht NordrheinWestfalen (LSG) in sechs Verfahren ent- schieden (Aktenzeichen u.a. L $16 \mathrm{KR}$ 646/12 KL). Die Urteile sind nicht rechtskräftig.

\section{Verzerrung durch Rechenfehler}

Die Knappschaft, die AOKen und einige Betriebskrankenkassen hatten gegen das Berechnungsverfahren für den Morbi-
RSA geklagt. Dabei ging es um die aus ihrer Sicht unangemessene Berücksichtigung der Kosten für die Behandlung von Patienten, die im Laufe eines Jahres gestorben sind. Bislang werden die Kosten auf das ganze Jahr hochgerechnet, bei der Zuweisung der Pauschalen aus dem Gesundheitsfonds aber nur die Tage berücksichtigt, an denen sie tatsächlich gelebt haben.

Der wissenschaftliche Beirat für die Weiterentwicklung des RSA hat sich schon länger für eine Änderung des Ver- 